\title{
The Relationship Between Helicobacter pylori and Inflammatory Bowel Disease
}

\author{
Yufen Zhong, MD'; Zhongchen Zhang, $\mathrm{MD}^{1}$; Yingying Lin, $\mathrm{MD}^{1}$; Lili $\mathrm{Wu}, \mathrm{MD}^{2 *}$ \\ 'Department of Gastroenterology, The First People's Hospital of Wenling, Wenling, Zhejiang, China \\ ${ }^{2}$ Taizhou Cancer Hospital, Wenzhou Medical University, Wenling, Zhejiang, China
}

\begin{abstract}
Background: Helicobacter pylori may have a protective effect against inflammatory bowel disease (IBD). We integrated epidemiological data to identify the correlation between IBD and H. pylori. Moreover, we analyzed whether IBD medication and classification affect H. pylori, and whether eradication of H. pylori leads to recurrence of IBD.

Methods: Articles published up to May 1, 2019, in three main databases including PubMed, MEDLINE and Embase, were searched. Study types included cross-sectional studies, retrospective studies and perspective studies, and data were combined and analyzed. Spearman correlation analysis and meta-analysis were performed after collecting and collating the relevant data. Sensitivity analysis and meta-regression were used to evaluate reliability and heterogeneity.

Results: Fifty-nine studies on IBD prevalence, 127 studies on $H$. pylori prevalence, and 23 studies for meta-analysis were included. IBD, ulcerative colitis (UC) and Crohn's disease (CD) were negatively correlated to $H$. pylori prevalence (all $P<0.001$ ). The metaanalysis results showed that compared to controls, the odds of having $H$. pylori infection were $0.44,0.36,0.54$ for IBD, CD and $\mathrm{UC}$, respectively $(\mathrm{OR}=0.44,95 \% \mathrm{Cl}=0.34-0.59 ; \mathrm{OR}=0.36,95 \% \mathrm{Cl}=0.26-0.49 ; \mathrm{OR}=0.54,95 \% \mathrm{Cl}=0.4-0.72)$. Moreover, IBD patients were 1.41 times $(\mathrm{OR}=1.41,95 \% \mathrm{Cl}=1.25-1.58)$ more likely to relapse after eradication of $H$. pylori. Finally, H. pylori infection was not related to IBD medication and classification.

Conclusion: H. pylori prevalence was negatively correlated to IBD and H. pylori had a protective effect against IBD. Furthermore, eradication of $H$. pylori can lead to recurrence of IBD.

Keywords: Crohn disease, Helicobacter pylori, Inflammatory bowel diseases, Ulcerative colitis

Cite this article as: Zhong Y, Zhang Z, Lin Y, Wu L. The relationship between helicobacter pylori and inflammatory bowel disease. Arch Iran Med. 2021;24(4):317-325. doi: 10.34172/aim.2021.44
\end{abstract}

Received: August 9, 2020, Accepted: November 16, 2020, ePublished: April 1, 2021

\section{Introduction}

Inflammatory bowel disease (IBD), including ulcerative colitis (UC) and Crohn's disease (CD), comprises chronic gastrointestinal disorders characterized by dysregulated intestinal inflammation. ${ }^{1,2}$ There are regional differences in the incidence of IBD, which is higher in developed countries, while lower in developing countries. However, the incidence in developing countries has also been rising in recent years. ${ }^{3}$ The pathophysiology of IBD is unknown, which involves interactions with genetic susceptibility, environmental factors, immune dysregulation and imbalance of gut microbiota. ${ }^{4-7}$

Due to its ability to reflect the cellular immune response driven by continuous activity of the host immune system, many scholars have already paid attention to the correlation between IBD and Helicobacter pylori. ${ }^{8} \mathrm{H}$. pylori is one of the most widespread chronic bacterial infections which can cause peptic ulcer, chronic gastritis, and gastric cancer. ${ }^{9}$ It also seems to have a close relationship with extra-gastric diseases. ${ }^{10}$ Potential protective effects of $H$. pylori on IBD have been provided in published data. ${ }^{11,12}$ Rokkas et al reported a meta-analysis on $H$. pylori and
IBD, although it had some shortcomings. ${ }^{11}$ The $H$. pylori diagnosis was made by serologic testing in some studies, while serologic false-positive and false-negative rates are high. ${ }^{13}$ As antibodies persist for a long time, serologic IgG test has less than $80 \%$ specificity for active $H$. pylori infection. ${ }^{14}$ In addition, some studies have clearly included patients with dyspepsia, constipation and irritable bowel syndrome (IBS) as control groups. However, H. pylori infection is closely related to these diseases. ${ }^{15,16}$ These two points affected the reliability of the entire meta-analysis to some extent. Furthermore, the meta-analysis of selected articles only analyzed a small number of individuals in a certain region, which did not reflect the IBD prevalence in high-risk areas of $H$. pylori worldwide. Epidemiological evidence can greatly increase the reliability of conclusions.

In this systematic review, studies which met the requirements were collected and used for systematic comparison. We firstly aimed to collect articles addressing the prevalence of IBD and $H$. pylori all over the world and clarifying the correlation. The second purpose was to conduct a meta-analysis to further verify the correlation by optimizing screening criteria. Furthermore, we tried 
to find the relationship between IBD medication and $H$. pylori, disease severity and $H$. pylori. Finally, we attempted to find out whether $H$. pylori eradication affects IBD recurrence. This study would provide a comprehensive view of the relationship between IBD and $H$. pylori.

\section{Materials and Methods}

\section{Data Sources and Study Selection}

The authors searched English-language papers published up to May 1, 2019, in three main databases including PubMed, MEDLINE and Embase. In addition, the following three screening schemes were used: 1) ((prevalence) OR (epidemiolog*)) AND ((IBD) OR (inflammatory bowel disease) OR (CD) OR (Crohn's disease) $O R$ (UC) OR (ulcerative colitis)), which was used to screen for IBD prevalence. 2) ((prevalence) $O R$ (epidemiolog*)) AND ((Helicobacter pylori) OR (H. pylori) OR (HP)). Based on the IBD prevalence, this scheme was used to screen for $H$. pylori prevalence. 3) ((IBD) OR (inflammatory bowel disease) $O R$ (CD) OR (Crohn's disease) OR (UC) OR (ulcerative colitis)) AND ((Helicobacter pylori) OR (H. pylori) $O R(H P))$, which was used to screen articles for meta-analysis.

Inclusion criteria for the correlation analysis were: 1) epidemiological data from Jan 1, 2000; 2) reports on adults; 3) reporting both IBD prevalence and $H$. pylori prevalence in an area; 4) the ability of combined and analyze the data. Inclusion criteria for the meta-analysis were: 1) data referring to the correction of $H$. pylori and IBD, 2) $H$. pylori was diagnosed by histology and/or UBT and/or RUT and/or bacterial culture, not serologic tests, 3) controls were healthy individuals, 4) reports on adults.

\section{Data Extraction}

Two authors independently examined papers which may be available and a third author double-checked them. If there was ambiguity, another author evaluated the study again. The Preferred Reporting Items for Systematic Reviews and Meta-Analyses (PRISMA) statement was followed. ${ }^{17}$

\section{Statistical Analysis}

IBD (including CD and UC) prevalence $\left(/ 10^{5}\right)$ and $H$. pylori prevalence (\%) for each country or region were estimated by pooling the data. Statistical heterogeneity was evaluated by Cochran's Q-test and the $\mathrm{I}^{2}$ statistic. In addition, the random effects model was used to calculate pooled results. Spearman correlation analysis was performed to demonstrate whether $H$. pylori was negatively correlated to IBD.

Odds ratios (ORs) with 95\% CIs were used to describe the ratio of $H$. pylori occurring in IBD patients vs. controls, $H$. pylori occurring by IBD medication, $H$. pylori occurring by IBD classification and recurrence of IBD after $H$. pylori eradication. The Fixed-model method (if $\mathrm{I}^{2} \leq 50 \%, P>0.1$ ) or random-model method (if $\mathrm{I}^{2}>50 \%, P \leq 0.1$ ) was selected in the study. ${ }^{18,19}$ In addition, standardized mean difference (SMD) was used to describe Crohn's disease activity index (CDAI) and C-reactive protein (CRP) pre- or post- $H$. pylori eradication.

Sensitivity analysis was done to evaluate the stability of the study. Meta-regression was used to look for sources of heterogeneity. All analyses were conducted using STATA 15.1 (StataCorp., College Station, Texas, USA) or SPSS 25.0 (IBM, Chicago, IL, USA).

\section{Results}

\section{Basic Characteristics}

Figure 1 presents the flowchart describing the process. A total of 17919 articles entered the screening list for IBD
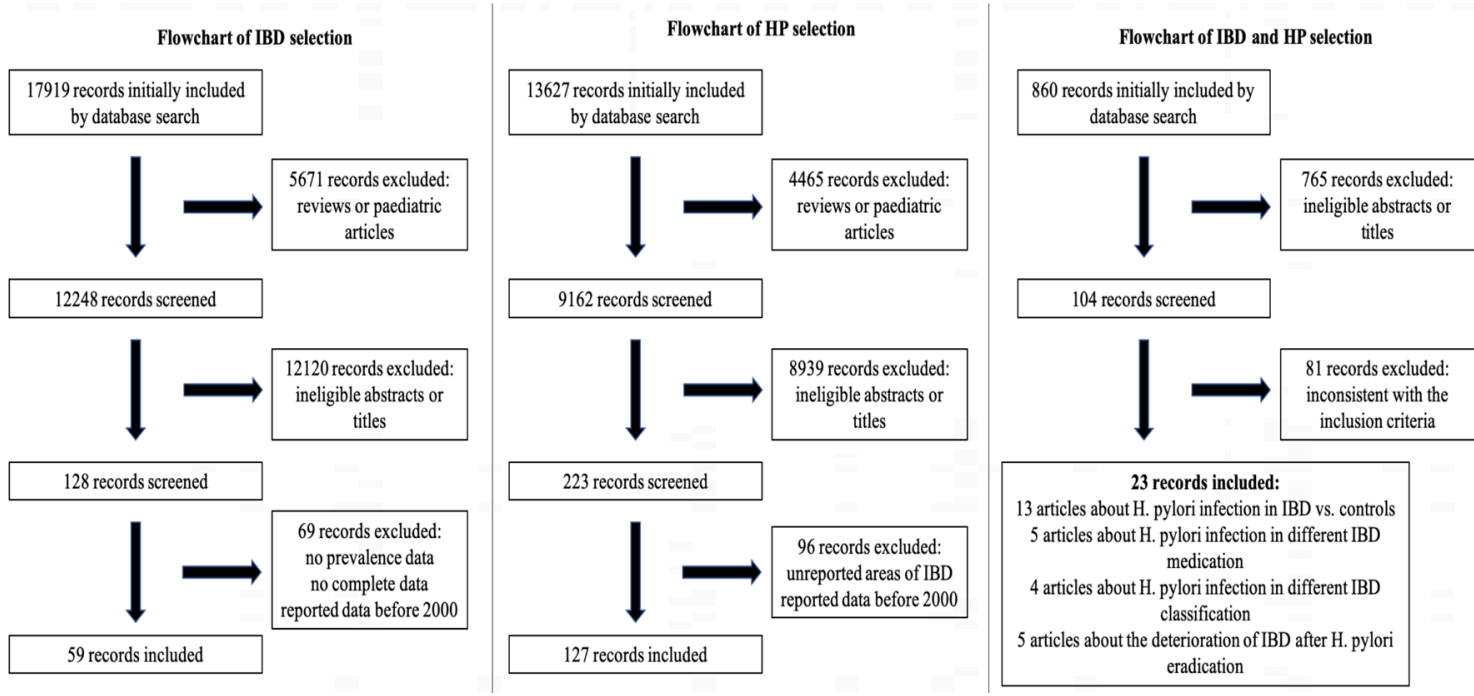

Figure 1. Flowchart Describing the Process of Study Selection 
prevalence, 13627 for $H$. pylori prevalence and 860 for meta-analysis. Finally, 59 articles for IBD prevalence (Supplementary file 1), 127 articles for $H$. pylori prevalence (Supplementary file 1) and 23 articles for meta-analysis were found eligible for our research (Supplementary file 2). We selected the prevalence data of the UK in the 1990s because of data limitations. Epidemiological data covered 6 continents and 33 countries or regions (Table 1).

\section{Correlation Between IBD Prevalence and Helicobacter pylori Prevalence}

The main characteristics of IBD prevalence and $H$. pylori prevalence are presented in Table 1 . The pooling data showed that in North America, Europe, and Oceania, which consist of developed countries, the IBD prevalence was high $\left(378.8 / 10^{5}, 95 \% \mathrm{CI}=241.5-516 / 10^{5} ; 372.6 / 10^{5}\right.$, $95 \%$ CI $=292.6-452.6 / 10^{5} ; 308.6 / 10^{5}$, 95\% CI $=270.3-$ $346.9 / 10^{5}$, respectively), while the $H$. pylori prevalence was low $(22.5 \%, 95 \% \mathrm{CI}:=20.4-24.7 \% ; 36.9 \%, 95 \%$ $\mathrm{CI}=32.7-41.2 \% ； \quad 32.9 \% ， \quad 95 \% \quad \mathrm{CI}=19.4-46.4 \%$, respectively) (Figure $2 \mathrm{~B}$ ). On the contrary, the IBD prevalence was low $(37.6 / 105,95 \% \mathrm{CI}=14.7-60.5 / 105$; 50.6/105, 95\% CI $=35.1-66.2 / 105 ; 31.6 / 105,95 \%$ $\mathrm{CI}=28.0-35.2 / 105$, respectively), while the $H$. pylori prevalence was high $(63.7 \%, 95 \% \mathrm{CI}=52.8-74.6 \%$; $47.8 \%, 95 \% \mathrm{CI}=45.1-50.4 \%$; 68.3\%, 95\% CI $=46.8-$ 89.7\%, respectively) in South America, Asia, and Africa, which are mostly developing countries (Figure 2B).

Table 1. Prevalence of IBD, CD, UC and H. pylori Since 2000 Across the World.

\begin{tabular}{|c|c|c|c|c|c|}
\hline Country/Region & $\begin{array}{l}\text { No. of Reporting } \\
\text { Studies (IBD/HP) }\end{array}$ & $\begin{array}{l}\text { HP Prevalence } \\
\text { Estimates, \% } \\
(95 \% \mathrm{Cl})\end{array}$ & $\begin{array}{l}\text { IBD Prevalence } \\
\text { Estimates, }\left(/ 10^{5}\right) \\
(95 \% \mathrm{CI})\end{array}$ & $\begin{array}{c}\text { CD Prevalence } \\
\text { Estimates, }\left(/ 10^{5}\right) \\
(95 \% \mathrm{CI})\end{array}$ & $\begin{array}{l}\text { UC Prevalence } \\
\text { Estimates, }\left(/ 10^{5}\right) \\
(95 \% \mathrm{Cl})\end{array}$ \\
\hline \multicolumn{6}{|c|}{ North America $(n=11 / 14)$} \\
\hline USA & $6 / 10$ & $22.0(19.6-24.4)$ & $450.2(405.5-494.9)$ & $212.2(164.7-259.7)$ & $238.1(223.0-253.2)$ \\
\hline Canada & $3 / 3$ & $22.5(9.7-35.2)$ & $468.4(355.3-581.6)$ & $249.7(225.8-273.5)$ & $213.2(121.4-305.0)$ \\
\hline Puerto Rico & $2 / 1$ & $33.0(29.0-37.0)$ & $31.5(18.4-44.6)$ & $10.4(1.5-19.2)$ & $17.9(7.3-28.5)$ \\
\hline \multicolumn{6}{|c|}{ South America $(n=5 / 7)$} \\
\hline Brazil & $4 / 5$ & $64.4(53.2-75.5)$ & $30.4(3.6-57.2)$ & $11.8(0-24.4)$ & $18(3.8-32.3)$ \\
\hline Chile & $1 / 2$ & $61.7(36.1-87.4)$ & $66.6(65.5-67.8)$ & $20.8(20.1-21.4)$ & $45.9(44.9-46.8)$ \\
\hline \multicolumn{6}{|c|}{ Oceania $(n=4 / 7)$} \\
\hline New Zealand & $2 / 2$ & $26.5(11-42.1)$ & $277.1(215.2-339.1)$ & $142.1(115.1-169.1)$ & $121.7(75.5-167.8)$ \\
\hline Australia & $2 / 5$ & $35.4(16.4-54.4)$ & $338.4(325.8-351.1)$ & $183.2(156.8-209.6)$ & $146.6(126.5-166.7)$ \\
\hline \multicolumn{6}{|c|}{ Asia $(n=14 / 52)$} \\
\hline Taiwan, China & $2 / 4$ & $51.1(40-62.1)$ & $10.2(8.6-11.7)$ & $1.9(1.6-2.2)$ & $8.3(7.0-9.5)$ \\
\hline Hong Kong, China & $1 / 3$ & $41.1(36.5-45.8)$ & $45.8(44.0-47.6)$ & $17.5(16.4-18.6)$ & $27.4(26.0-28.8)$ \\
\hline Japan & $1 / 9$ & $30.2(21.3-39.2)$ & $84.8(53.2-116.4)$ & $21.2(20.8-21.7)$ & $63.6(62.8-64.4)$ \\
\hline Korea & $1 / 21$ & $54.8(50.5-59.2)$ & $95.6(94.7-96.5)$ & $29.6(29.2-30.1)$ & $66.0(65.2-66.7)$ \\
\hline Malaysia & $3 / 4$ & $37.4(29.6-45.2)$ & $12.1(1.2-23.1)$ & $3.8(0.8-6.8)$ & $8.2(0.2-12.2)$ \\
\hline Sri Lanka & $2 / 1$ & $70.2(58.3-82.1)$ & $7.1(5.9-8.3)$ & $1.7(0.7-2.8)$ & $5.4(4.8-5.9)$ \\
\hline India & $1 / 2$ & $64.7(55.2-74.2)$ & - & - & $44.3(26.2-62.4)$ \\
\hline Israel & $1 / 4$ & $54.2(48.8-59.5)$ & $332.1(326.3-338)$ & $162.6(158.2-166.7)$ & $169.5(165.3-173.7)$ \\
\hline Turkey & $1 / 3$ & $79.0(73.9-84.1)$ & - & - & $4.8(3.5-6.2)$ \\
\hline Lebanon & $1 / 1$ & $51.9(46.3-57.5)$ & $159.2(95.6-222.9)$ & $53.1(16.8-89.9)$ & $106.2(54.2-158.1)$ \\
\hline \multicolumn{6}{|c|}{ Europe $(n=24 / 46)$} \\
\hline UK* $^{*}$ & $2 / 5$ & $29.0(14.1-43.9)$ & $340.8(240.5-441.1)$ & $127.7(97.7-157.7)$ & $208.9(143.9-273.9)$ \\
\hline Sweden & $2 / 2$ & $13.3(8.8-17.8)$ & $813.1(497-1129.3)$ & $304.1(88.6-519.6)$ & $439.5(261.3-617.6)$ \\
\hline Denmark & $2 / 5$ & $19.5(18.8-31.8)$ & $660.5(238.3-1082.8)$ & $207.5(97.0-318.1)$ & $453.1(141.4-764.8)$ \\
\hline Finland & $1 / 2$ & $31.9(0-70.2)$ & 595.0 (589.0-602.0) & - & - \\
\hline Italy & $3 / 3$ & $25.3(18.9-31.8)$ & $202.0(120.5-283.4)$ & $15(0.1-30)$ & $83.5(20.2-146.7)$ \\
\hline Spain & $2 / 4$ & $49.2(40.9-57.4)$ & 374.5 (39.6-709.4) & $154.1(80.6-227.5)$ & $219.3(0-483.1)$ \\
\hline Croatia & $3 / 2$ & $44.2(38.9-49.5)$ & $144.3(70.6-218.1)$ & $53.3(17.6-88.9)$ & $90.1(55.1-125.0)$ \\
\hline Switzerland & $2 / 1$ & $18.9(13.1-24.7)$ & $306.8(108.5-505.2)$ & 100.7 (91.9-109.5) & $105.0(96.0-125.0)$ \\
\hline Portugal & $1 / 3$ & $59.1(33.9-84.3)$ & $146.0(116.0-175.0)$ & $73.0(58.0-87.0)$ & $71.0(56.0-85.0)$ \\
\hline German & $1 / 7$ & $34.5(28.5-40.4)$ & $744.0(707.0-755.0)$ & $322.0(302.0-346.0)$ & $412.0(389.0-436.0)$ \\
\hline Netherlands & $1 / 2$ & $35.5(28.2-42.7)$ & $444.2(421.5-467.0)$ & $176.1(161.7-190.4)$ & $231.4(215.0-247.8)$ \\
\hline France & $1 / 2$ & $20.2(15.4-25.0)$ & $276.3(272.0-280.5)$ & $161.1(157.9-164.4)$ & $104.0(101.4-106.6)$ \\
\hline Poland & $1 / 4$ & $60.0(42.3-77.6)$ & 157.0 (155.0-159.0) & $35.0(33.0-36.0)$ & $112.1(111.0-113.1)$ \\
\hline Romania & $1 / 2$ & $68.6(60.2-76.9)$ & $3.9(3.6-4.2)$ & $1.5(1.3-1.7)$ & $2.4(2.2-2.7)$ \\
\hline Hungary & $1 / 2$ & $27.5(19.0-36.0)$ & $550.0(540.0-546.0)$ & $200.0(190.0-200.0)$ & $340.0(330.0-340.0)$ \\
\hline \multicolumn{6}{|c|}{ Africa $(n=1 / 2)$} \\
\hline Algeria & $1 / 2$ & $68.3(46.8-89.7)$ & $31.6(28.0-35.2)$ & $19.0(16.2-21.8)$ & $10.6(8.5-12.7)$ \\
\hline
\end{tabular}

IBD, inflammatory bowel disease; CD, Crohn's disease; UC, ulcerative colitis; HP, Helicobacter pylori; USA, United States of America; UK, United Kingdom. *All data are from the 1990s. 


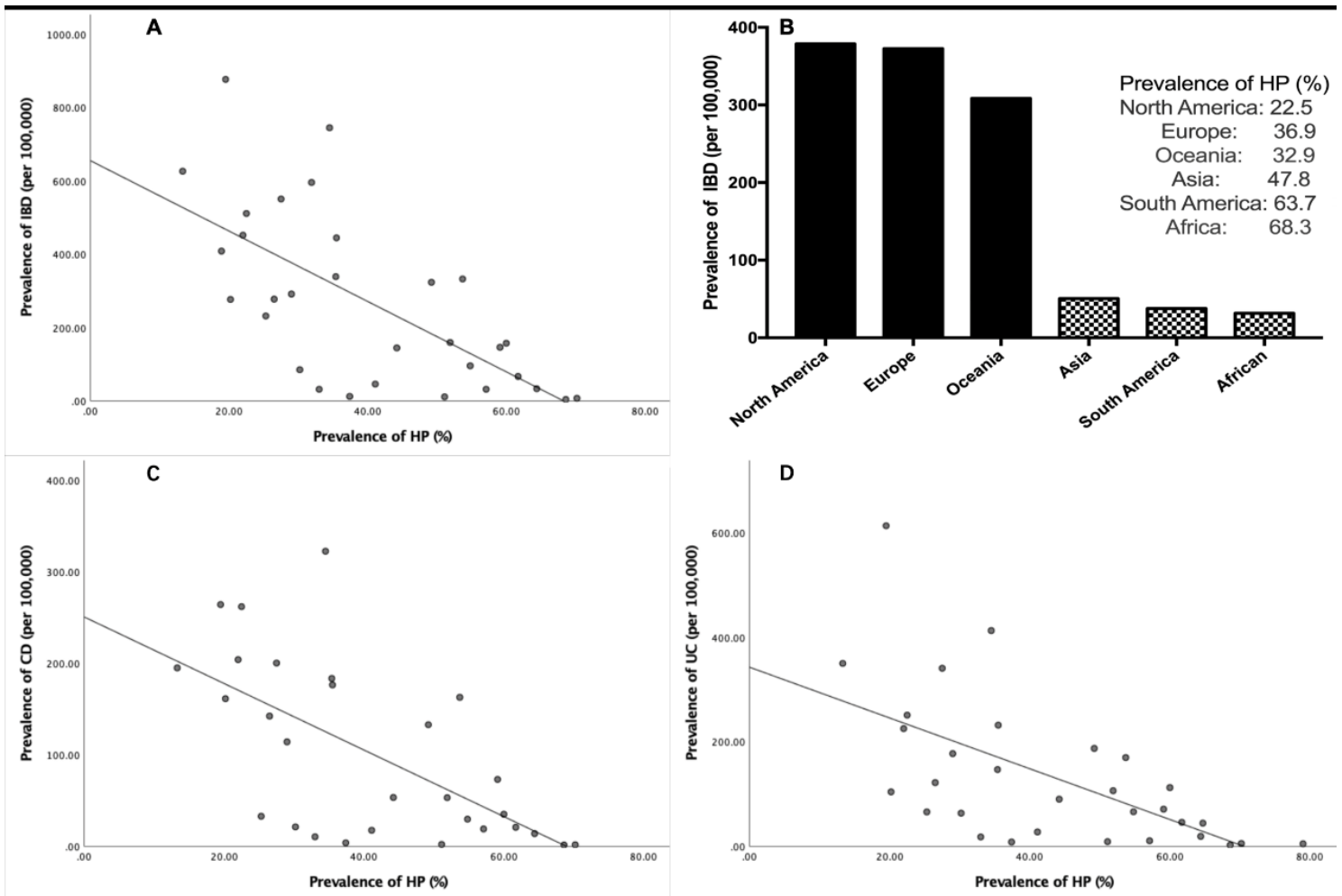

Figure 2. A, C, D) H. pylori prevalence was negatively correlated to IBD, $C D, \cup C$ prevalence (coefficient $=-0.679, P<0.001$; coefficient $=-0.616, P<0.001$; coefficient $=-0.666, P<0.001$ ). B) A continent with more developed countries had higher IBD prevalence and lower H. pylori prevalence; while a continent with more developing countries had lower IBD prevalence and higher $H$. pylori prevalence.

Spearman correlation analysis showed that $H$. pylori prevalence was negatively correlated to IBD prevalence (coefficient $=-0.679, P<0.001)$ (Figure $2 \mathrm{~A})$. In addition, H. pylori prevalence was negatively correlated to both $\mathrm{CD}$ prevalence (coefficient $=-0.616, P<0.001)$ (Figure 2C) and UC prevalence (coefficient $=-0.666, P<0.001$ ) (Figure 2D).

Helicobacter pylori Prevalence in IBD Patients vs Controls

The main characteristics of included papers for metaanalysis are shown in Supplementary file 2. We found that IBD patients were 0.44 times $(\mathrm{OR}=0.44,95 \%$ $\left.\mathrm{CI}=0.34-0.59, \mathrm{I}^{2}=80.1 \%, P<0.01\right)$ more likely to have H. pylori infection compared to controls (Figure $3 \mathrm{~A}$ ). CD patients were 0.36 times $(\mathrm{OR}=0.36,95 \% \mathrm{CI}=0.26$ $\left.0.49, \mathrm{I}^{2}=67.6 \%, P<0.01\right)$ more likely to have $H$. pylori infection compared to controls (Figure $3 \mathrm{~B}$ ). In addition, UC patients were 0.54 times $(\mathrm{OR}=0.54,95 \% \mathrm{CI}=0.4-$ $\left.0.72, \mathrm{I}^{2}=76.9 \%, P<0.01\right)$ more likely to have $H$. pylori infection compared to controls (Figure 3C). The H. pylori prevalence rates of IBD, CD, UC were all lower than the controls.

Helicobacter pylori Occurring in Different IBD Medications

Five articles described different $H$. pylori prevalence rates with different IBD medication. The drugs included sulfasalazine, mesalazine, corticosteroids and immunosuppressants. Sulfasalazine and mesalazine were put in the same class due to their similar pharmacological effects. Corticosteroids and immunosuppressants were classified into another class because of the effect of inhibiting the body's immune system. But, there was no difference in terms of $H$. pylori infection between the two classes $\left(\mathrm{OR}=2.02,95 \% \mathrm{CI}=1.0-4.09, \mathrm{I}^{2}=56.3 \%\right.$, $P=0.057$ ) (Figure 4A).

Helicobacter pylori Occurring in Different IBD Classes

According to the collected data, we classified moderate and severe IBD condition into one class, while remission and mild cases were placed into another class. In two of four articles, the patients were diagnosed as $\mathrm{CD}$, while the others were UC. We found that more serious disease condition was not associated with lower $H$. pylori infection $\left(\mathrm{OR}=1.06,95 \% \mathrm{CI}=0.66-1.71, \mathrm{I}^{2}=33.3 \%, P=0.213\right)$ (Figure 4B). In subgroup analysis, neither $\mathrm{CD}(\mathrm{OR}=0.96$, $\left.95 \% \mathrm{CI}=0.48-1.92, \mathrm{I}^{2}=77.2 \%, \mathrm{P}=0.036\right)$ nor $\mathrm{UC}$ $\left(\mathrm{OR}=1.17, \quad 95 \% \quad \mathrm{CI}=0.6-2.26, \quad \mathrm{I}^{2}=0 \%, \quad P=0.846\right)$ affected $H$. pylori infection (Figure 4B).

Recurrence of IBD after Helicobacter pylori Eradication A total of five articles were selected for this section. First of all, the $H$. pylori eradication plans chosen in the five articles were not consistent. Two articles used seven-day triple therapy, one article used fourteen-day triple therapy, one article used fourteen-day therapy without reporting the prescription, and one article used five- plus five-day sequential therapy. Three articles described the recurrence rate of IBD post $-H$. pylori eradication. IBD patients were 1.41 times $\left(\mathrm{OR}=1.41,95 \% \mathrm{CI}=1.25-1.58, \mathrm{I}^{2}=0 \%\right.$, 


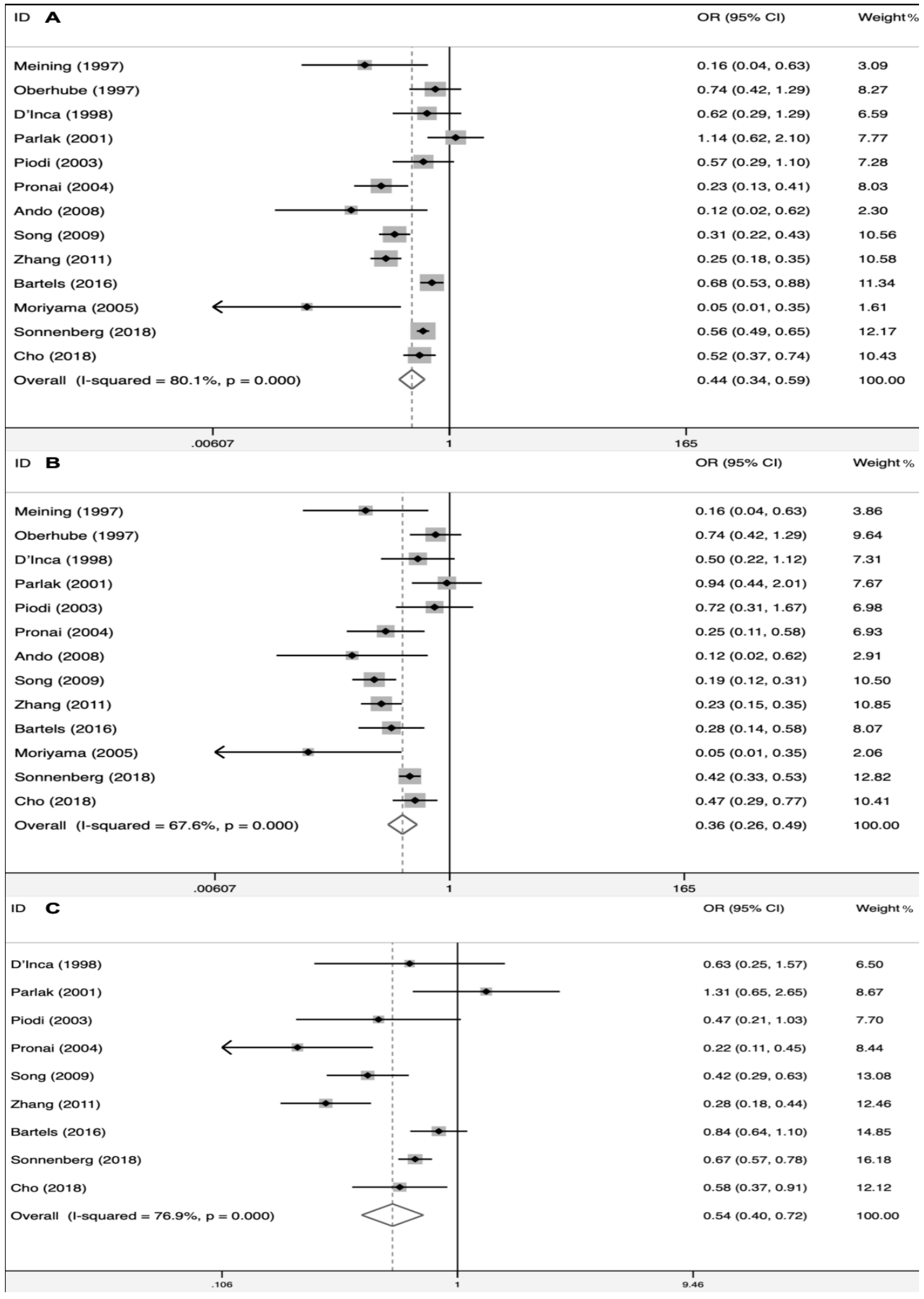

Figure 3. IBD, CD and UC patients were $0.44,0.36,0.54$ times more likely to have $H$. pylori infection compared to controls, respectively $(\mathrm{OR}=0.44,95 \% \mathrm{Cl}=0.34-0.59 ; \mathrm{OR}=0.36,95 \% \mathrm{Cl}=0.26-0.49 ; \mathrm{OR}=0.54,95 \% \mathrm{Cl}=0.4-0.72)$.

$P=0.728)$ more likely to relapse post $-H$. pylori eradication compared to those without H. pylori eradication (Figure 5), which showed that $H$. pylori eradication was a risk factor. When we removed a group of data with large weight, the results of the two external sets of data were not statistically significant $(\mathrm{OR}=1.34,95 \% \mathrm{CI}=0.75-2.38$, $\left.\mathrm{I}^{2}=0 \%, P=0.434\right)$. In addition, post $H$. pylori eradication, CRP (SMD $=-0.05,95 \% \mathrm{CI}=-3.09-3.02, \mathrm{I}^{2}=91.3 \%$, $P=0.001)$ and CDAI $(\mathrm{SMD}=0.06,95 \% \mathrm{CI}=-0.41-0.53$, $\left.\mathrm{I}^{2}=0 \%, P=0.678\right)$ had no statistical difference. 


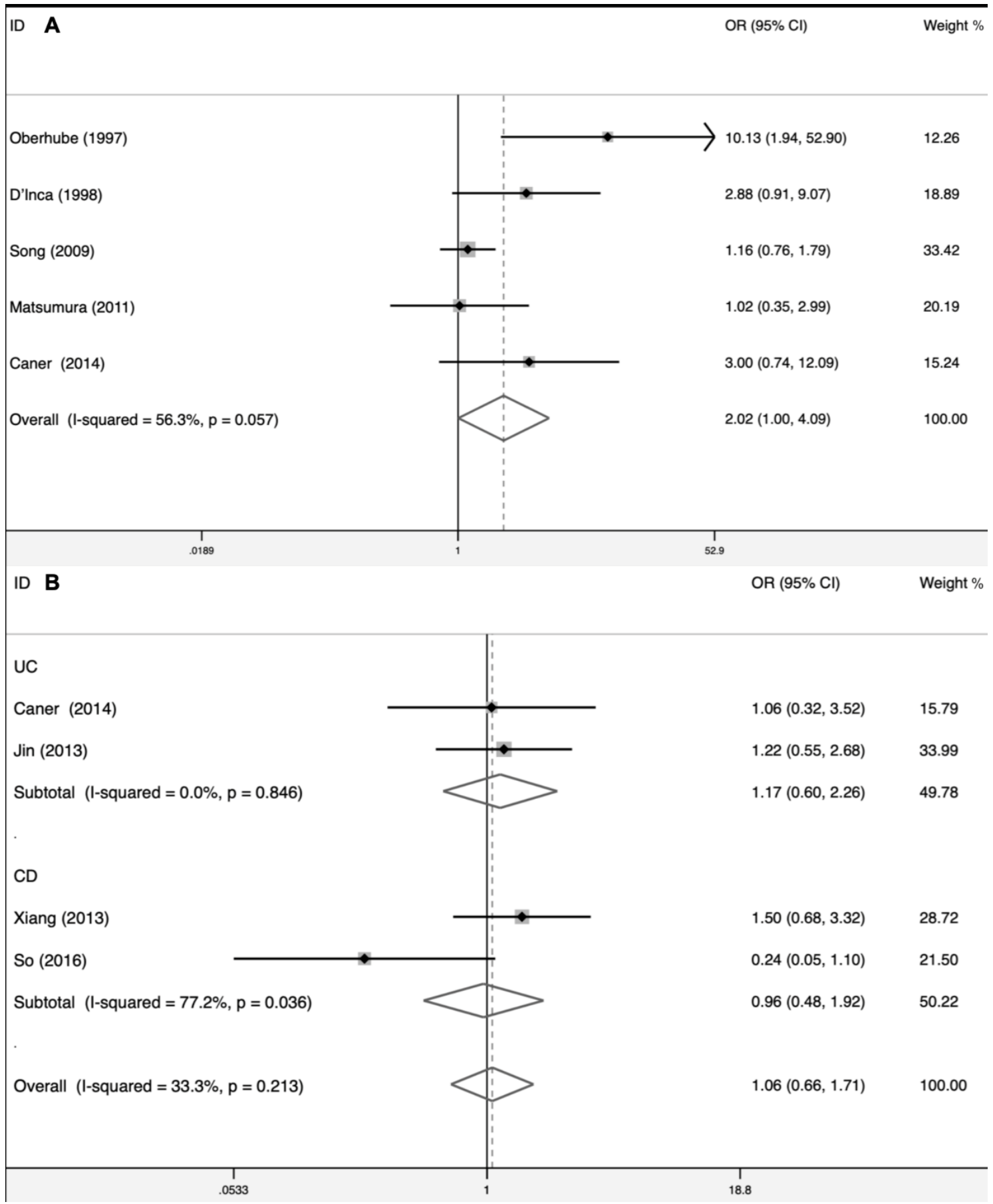

Figure 4. A) There was no difference in $\mathrm{H}$. pylori prevalence rates between the two classes $(\mathrm{OR}=2.02,95 \% \mathrm{Cl}=1.0-4.09)$. B) Serious disease condition of IBD, $C D$ and $U C$ did not have lower $H$. pylori infection $(\mathrm{OR}=1.06,95 \% \mathrm{Cl}=0.66-1.71$; $\mathrm{OR}=0.96,95 \% \mathrm{Cl}=0.48-1.92 ; \mathrm{OR}=1.17,95 \% \mathrm{Cl}=0.6-2.26)$.

\section{Sensitivity Analysis and Meta-regression}

Some meta-analysis results had heterogeneity. Through some methods, we aimed to identify the reliability of the results and look for sources of heterogeneity. Sensitivity analysis demonstrated that the results were stable and reliable. No article showed bias in the analysis.

Meta-regression proved that study districts $(P=0.817)$, study time $(P=0.987), H$. pylori test method $(P=0.333)$, multi-center or single-center study $(P=0.872)$, and number of individuals $(P=0.981)$ did not affect the results of meta-analysis on $H$. pylori prevalence in IBD patients. Also, CD and UC analysis did not find a heterogeneous source for study districts ( $P=0.922, P=1.000)$, study time $(P=0.983, P=0.998), H$. pylori test method $(P=0.148$, $P=0.759)$, multi-center or single-center study $(P=0.666$, $P=0.943)$, and number of individuals $(P=0.889$, $P=1.000)$. Moreover, combined medication $(P=0.869)$, immunosuppressant $(P=0.869)$ and $H$. pylori test method $(P=0.429)$ were not factors affecting heterogeneity of $H$. pylori prevalence in IBD medication. 


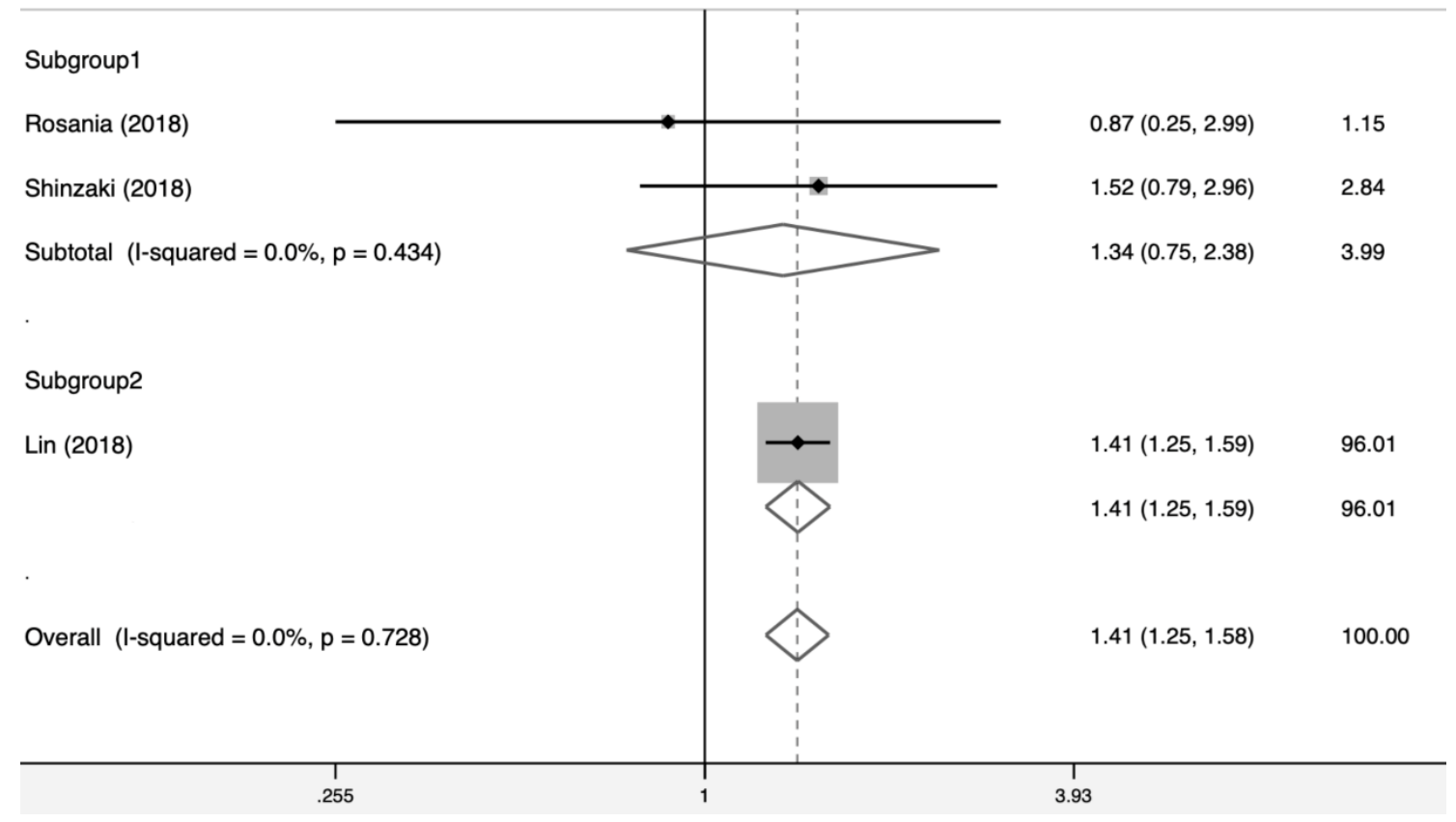

Figure 5. IBD patients were 1.41 times $(\mathrm{OR}=1.41,95 \% \mathrm{Cl}=1.25-1.58)$ more likely to relapse after $H$. pylori eradication compared to those without $H$. pylori eradication.

\section{Discussion}

Relevant preliminary studies data suggested a potential protective effect for $H$. pylori against IBD. The findings of this study demonstrated that $H$. pylori was negatively correlated to IBD through the collection of global epidemiological data. The meta-analysis was consistent with the conclusions that $H$. pylori was a key protective factor against IBD. Furthermore, post-H. pylori eradication, the recurrence of IBD was obviously worse, which provided strong evidence for $H$. pylori as a protective factor. Other results showed that $H$. pylori was not related to IBD medication and classification.

The potential mechanism of $H$. pylori in preventing IBD is still unknown. The influence of immune regulation is a universally recognized factor. Twenty years ago, D'Elios et al reported results indicating that $H$. pylori-specific $\mathrm{T}$ cell clones exhibited a Th2-like phenotype and produced IL-5 or IL-4 together with INF- $\alpha .{ }^{20}$ In vitro, it showed that H. pylori infection protects against DSS-induced colitis via decreasing Th17, balancing Th17/Treg responses and shifting macrophages to anti-inflammatory M2 phenotype. ${ }^{21}$ Engler et al confirmed that the protective factor was dependent on the IL-18 signaling and NLRP3 inflammasome. ${ }^{22}$ Other studies revealed that $H$. pylori has been associated with increased expression of Foxp3, which changes host immune response and diverts it away from the inflammatory Th1/Th17 pathway. ${ }^{23,24}$

The role of $H$. pylori DNA may be another important factor for protecting IBD. Luther et al conducted in-vitro research revealing that $H$. pylori DNA can down-regulate pro-inflammatory responses from dendritic cells (DCs) and attenuate DSS-induced colitis. ${ }^{25}$ Meanwhile, another study found that the inhibitory effect of $H$. pylori genomic DNA is restricted to the TLR-9 signaling pathway in the pathogenesis of IBD. ${ }^{26}$ Furthermore, CagA gene of $H$. pylori strains resulted in higher production of $\beta$-defensins. As is well-known, production of altered human defensin is associated with IBD pathogenesis. ${ }^{27,28}$ Compared to mutant $H$. pylori strains, one study demonstrated that the Th2 cytokine response protecting against DSS-colitis was CagA dependent. ${ }^{29}$

It is established that the treatment of IBD patients with anti-TNF- $\alpha$ agents, immunosuppressant and/ or corticosteroid increases the risk of infections. ${ }^{30}$ However, there is very little direct evidence in $H$. pylori infection. Conlan et al found that imunosuppression by a corticosteroid failed to exacerbate $H$. pylori infection in an in-vitro model. ${ }^{31}$ In a clinical study, similar results were found, showing that treatment of IBD patients with antiTNF- $\alpha$ factors and immunosuppressants did not influence the prevalence of $H$. pylori infection. ${ }^{32}$ Our meta-analysis results also confirmed that the use of immunosuppressive drugs did not affect $H$. pylori infection.

Intestinal microbiota may be another key factor. ${ }^{33}$ In certain murine colitis models, many research findings indicate that a single symbiotic organism has the ability to induce colitis, which may have a relationship to human IBD. ${ }^{33}$ It was shown that long-term $H$. pylori infection 
can cause significant changes in the composition of the large intestine microbiota, which indicates that $H$. pylori may regulate the intestinal microflora, thereby affecting the occurrence of IBD. ${ }^{34}$ In clinical applications, related articles demonstrated that probiotics and fecal microbiota transplantation were associated with a significant improvement in the treatment of IBD. ${ }^{35,36}$ In this metaanalysis, we found that the recurrence rate of IBD was high after $H$. pylori eradication. Is this related to intestinal flora imbalance? One study observed that eradication of $H$. pylori alters gut microbiota, specifically Lachnobacterium, B. adolescentis and Coriobacteriaceae. ${ }^{37}$ Martin-Nunez et al also demonstrated that infection and eradication of $H$. pylori with antibiotics cause alterations in gut microbiota. ${ }^{38}$ Furthermore, one study indicated that exposure to antibiotics during pregnancy is associated with increased risk of very early onset IBD regardless of gastroenteritis. ${ }^{39}$ Therefore, recurrence of IBD after $H$. pylori eradication may be related to gut microbiota imbalance.

This article has done a lot of work, but there were still some shortcomings. A large number of epidemiological data were collected and combined for correlation analysis, but it did not represent every country or region. For example, only one African country reported IBD prevalence. Studies of IBD prevalence basically included enough individuals to reflect the prevalence of the entire region, while such studies were not available for $H$. pylori prevalence. Although we statistically combined data, which did not fully reflect the overall $H$. pylori prevalence in the entire region. The final result may be affected by this factor. In addition, although the inclusion criteria were optimized, we excluded patients with functional dyspepsia in the control group. Several studies did not report whether there were such patients in the control group, which may have affected the results. Moreover, we ruled out some factors by meta-regression, but the included articles did not consider the effects of age, gender, lifestyle, smoking, etc. We lacked data for comprehensive analysis. The included articles for meta-analysis were mainly done in Europe and Asia, and data was lacking from other regions and developing countries. Although we found that IBD patients were 1.41 times more likely for recurrence after $H$. pylori eradication, one study had a large weight, which may have biased the results. Therefore, more randomized controlled studies are needed to improve the reliability of the results.

In conclusion, the epidemiological results and metaanalysis results of this study demonstrated that $H$. pylori infection is negatively correlated to IBD and $H$. pylori is a protective factor against IBD. In addition, $H$. pylori eradication might lead to the recurrence of IBD.

\section{Authors' Contribution}

YZh and LW designed research. YZh and ZhZh searched papers. YL evaluated the disagreement. ZhZh conducted the statistical analysis. YZh wrote the paper and LW revised the paper.

\section{Conflict of Interest Disclosures \\ None.}

\section{Ethical Statement}

Not applicable.

\section{Funding}

This study was supported by Social development science and technology plans of Taizhou (XM2020621).

\section{Supplementary Materials}

Supplementary file 1. Prevalence of IBD, CD, UC and H. pylori since 2000 all over the world.

Supplementary file 2. Included articles for analysis in this study.

\section{References}

1. Torres J, Mehandru S, Colombel JF, Peyrin-Biroulet L. Crohn's disease. Lancet. 2017;389(10080):1741-55. doi: 10.1016/ S0140-6736(16)31711-1.

2. Ungaro R, Mehandru S, Allen PB, Peyrin-Biroulet L, Colombel JF. Ulcerative colitis. Lancet. 2017;389(10080):1756-70. doi:10.1016/S0140-6736(16)32126-2.

3. Ng SC, Shi HY, Hamidi N, Underwood FE, Tang W, Benchimol $\mathrm{El}$, et al. Worldwide incidence and prevalence of inflammatory bowel disease in the 21st century: a systematic review of population-based studies. Lancet. 2018;390(10114):27692778. doi: 10.1016/S0140-6736(17)32448-0.

4. Miyoshi J, Chang EB. The gut microbiota and inflammatory bowel diseases. Transl Res. 2017;179:38-48. doi: 10.1016/j. trsl.2016.06.002.

5. Park JH, Peyrin-Biroulet L, Eisenhut M, Shin JI. IBD immunopathogenesis: A comprehensive review of inflammatory molecules. Autoimmun Rev. 2017;16(4):41626. doi: 10.1016/j.autrev.2017.02.013.

6. Piovani D, Danese S, Peyrin-Biroulet L, Nikolopoulos GK, Lytras T, Bonovas S. Environmental Risk Factors for Inflammatory Bowel Diseases: an Umbrella Review of Metaanalyses. Gastroenterology. 2019;157(3):647-659.e4. doi: 10.1053/j.gastro.2019.04.016.

7. Uniken Venema WT, Voskuil MD, Dijkstra G, Weersma RK, Festen EA. The genetic background of inflammatory bowel disease: from correlation to causality. J Pathol. 2017;241(2):146-58. doi: 10.1002/path.4817.

8. Papamichael K, Konstantopoulos P, Mantzaris GJ. Helicobacter pylori infection and inflammatory bowel disease: is there a link?. World J Gastroenterol. 2014;20(21):6374-85. doi: 10.3748/wjg.v20.i21.6374.

9. Crowe SE. Helicobacter pylori Infection. N Engl J Med. 2019;380(12):1158-65. doi: 10.1056/NEJMcp1710945.

10. Kyburz A, Muller A. Helicobacter pylori and Extragastric Diseases. Curr Top Microbiol Immunol. 2017;400:325-47. doi: 10.1007/978-3-319-50520-6_14.

11. Rokkas T, GisbertJP, NivY, O'Morain C. The association between Helicobacter pylori infection and inflammatory bowel disease based on meta-analysis. United European Gastroenterol J. 2015;3(6):539-50. doi: 10.1177/2050640615580 889.

12. Wu XW, Ji HZ, Yang MF, Wu L, Wang FY. Helicobacter pylori infection and inflammatory bowel disease in Asians: a meta- 
analysis. World J Gastroenterol. 2015;21(15):4750-6. doi: 10.3748/wjg.v21.i15.4750.

13. Atkinson NS, Braden B. Helicobacter Pylori Infection: Diagnostic Strategies in Primary Diagnosis and After Therapy. Dig Dis Sci. 2016;61(1):19-24. doi: 10.1007/s10620-0153877-4.

14. Chey WD, Wong BC. American College of Gastroenterology guideline on the management of Helicobacter pylori infection. Am J Gastroenterol. 2007;102(8):1808-25. doi: 10.1111/j.1572-0241.2007.01393.x.

15. Du LJ, Chen BR, Kim JJ, Kim S, Shen JH, Dai N. Helicobacter pylori eradication therapy for functional dyspepsia: Systematic review and meta-analysis. World J Gastroenterol. 2016;22(12):3486-95. doi: 10.3748/wjg.v22.i12.3486.

16. Kato M, Ota H, Okuda M, Kikuchi S, Satoh K, Shimoyama $\mathrm{T}$, et al. Guidelines for the management of Helicobacter pylori infection in Japan: 2016 Revised Edition. Helicobacter. 2019;24(4):e12597. doi: 10.1111/hel.12597.

17. Liberati A, Altman DG, Tetzlaff J, Mulrow C, Gøtzsche PC, loannidis JP, et al. The PRISMA statement for reporting systematic reviews and meta-analyses of studies that evaluate health care interventions: explanation and elaboration. J Clin Epidemiol. 2009;62(10):e1-34. doi: 10.1016/j. jclinepi.2009.06.006.

18. Higgins JP, Thompson SG. Quantifying heterogeneity in a meta-analysis. Stat Med. 2002;21(11):1539-58. doi: 10.1002/ sim. 1186.

19. Jean Dunn O, A. Clark V. Basic statistics. A primer for biomedical sciences. 4th ed. John Wiley \& Sons. 2009.

20. D'Elios MM, Manghetti M, Almerigogna F, Amedei A, Costa F, Burroni D, et al. Different cytokine profile and antigenspecificity repertoire in Helicobacter pylori-specific $\mathrm{T}$ cell clones from the antrum of chronic gastritis patients with or without peptic ulcer. Eur J Immunol. 1997;27(7):1751-5. doi: 10.1002/eji.1830270723.

21. Zhang H, Dai Y, Liu Y, Wu T, Li J, Wang X, et al. Helicobacter pylori Colonization Protects Against Chronic Experimental Colitis by Regulating Th17/Treg Balance. Inflamm Bowel Dis. 2018;24(7):1481-92. doi: 10.1093/ibd/izy107.

22. Engler DB, Leonardi I, Hartung ML, Kyburz A, Spath S, Becher B, et al. Helicobacter pylori-specific protection against inflammatory bowel disease requires the NLRP3 inflammasome and IL-18. Inflamm Bowel Dis. 2015;21(4):85461. doi: 10.1097/MIB.0000000000000318.

23. Kao JY, Rathinavelu S, Eaton KA, Bai L, Zavros Y, Takami M, et al. Helicobacter pylori-secreted factors inhibit dendritic cell IL-12 secretion: a mechanism of ineffective host defense. Am J Physiol Gastrointest Liver Physiol. 2006;291(1):G73-81. doi: 10.1152/ajpgi.00139.2005.

24. Rad R, Brenner L, Bauer S, Schwendy S, Layland L, da Costa, CP, et al. CD25+/Foxp3+T cells regulate gastric inflammation and Helicobacter pylori colonization in vivo. Gastroenterology. 2006;131(2):525-37. doi: 10.1053/j.gastro.2006.05.001.

25. Luther J, Owyang SY, Takeuchi T, Cole TS, Zhang M, Liu M, et al. Helicobacter pylori DNA decreases pro-inflammatory cytokine production by dendritic cells and attenuates dextran sodium sulphate-induced colitis. Gut. 2011;60(11):14791486. doi: 10.1136/gut.2010.220087.

26. Owyang SY, Luther J, Owyang CC, Zhang M, Kao JY. Helicobacter pylori DNA's anti-inflammatory effect on experimental colitis. Gut Microbes. 2012;3(2):168-71. doi: 10.4161/gmic.19181.
27. Hornsby MJ, Huff JL, Kays RJ, Canfield DR, Bevins CL, Solnick JV. Helicobacter pylori induces an antimicrobial response in rhesus macaques in a cag pathogenicity island-dependent manner. Gastroenterology. 2008;134(4):1049-1057. doi: 10.1053/j.gastro.2008.01.018.

28. Ramasundara M, Leach ST, Lemberg DA, Day AS. Defensins and inflammation: the role of defensins in inflammatory bowel disease. J Gastroenterol Hepatol. 2009;24(2):202-8. doi: 10.1111/j.1440-1746.2008.05772.x.

29. Tepler A, Narula N, Peek Jr RM, Patel A, Edelson C, Colombel $J F$, et al. Systematic review with meta-analysis: association between Helicobacter pylori CagA seropositivity and odds of inflammatory bowel disease. Aliment Pharmacol Ther. 2019;50(2):121-31. doi: 10.1111/apt.15306.

30. Singh JA, Wells GA, Christensen R, Ghogomu ET, Maxwell L, Macdonald JK, et al. Adverse effects of biologics: a network meta-analysis and Cochrane overview. Cochrane Database Syst Rev. 2011;2011(2):CD008794. doi: 10.1002/14651858. CD008794.pub2.

31. Conlan JW, KuoLee R, Webb A, Perry MB. Imunosuppression by a corticosteroid fails to exacerbate Helicobacter pylori infection in a mouse model of gastric colonization. Can J Microbiol. 1999;45(11):975-980.

32. Triantafillidis JK, Gikas A, Merikas E. Treatment of inflammatory bowel disease patients with anti-TNF-alpha factors and immunosuppressives does not influence the prevalence of Helicobacter pylori infection. Indian J Gastroenterol. 2014;33(4):383-4. doi: 10.1007/s12664-013-0389-z.

33. Weingarden $A R$, Vaughn BP. Intestinal microbiota, fecal microbiota transplantation, and inflammatory bowel disease. Gut Microbes. 2017;8(3):238-52. doi: 10.1080/19490976.2017.1290757.

34. Heimesaat MM, Fischer A, Plickert $R$, Wiedemann $T$, Loddenkemper C, Göbel UB, et al. Helicobacter pylori induced gastric immunopathology is associated with distinct microbiota changes in the large intestines of long-term infected Mongolian gerbils. PLoS One. 2014;9(6):e100362. doi: 10.1371/journal.pone.0100362.

35. Colman RJ, Rubin DT. Fecal microbiota transplantation as therapy for inflammatory bowel disease: a systematic review and meta-analysis. J Crohns Colitis. 2014;8(12):1569-81. doi: 10.1016/j.crohns.2014.08.006.

36. Derwa Y, Gracie DJ, Hamlin PJ, Ford AC. Systematic review with meta-analysis: the efficacy of probiotics in inflammatory bowel disease. Aliment Pharmacol Ther. 2017;46(4):389-400. doi: 10.1111/apt.14203.

37. Cornejo-Pareja I, Martin-Nunez GM, Roca-Rodriguez MM, Cardona F, Coin-Aragüez L, Sánchez-Alcoholado L, et al. H. pylori Eradication Treatment Alters Gut Microbiota and GLP-1 Secretion in Humans. J Clin Med. 2019;8(4):451. doi: 10.3390/jcm8040451.

38. Martin-Nunez GM, Cornejo-Pareja I, Coin-Araguez L, RocaRodríguez MM, Muñoz-Garach A, Clemente-Postigo M, et al. $\mathrm{H}$. pylori eradication with antibiotic treatment causes changes in glucose homeostasis related to modifications in the gut microbiota. PLoS One. 2019;14(3):e0213548. doi: 10.1371/ journal.pone. 0213548 .

39. Ortqvist AK, Lundholm C, Halfvarson J, Ludvigsson JF, Almqvist C. Fetal and early life antibiotics exposure and very early onset inflammatory bowel disease: a population-based study. Gut. 2019;68(2):218-25. doi: 10.1136/gutjnl-2017-314352. 